\title{
Uma revoada de entidades: o que enxameia a atuação dos streamers nas jornadas de junho de 2013?
}

Lara Linhalis Guimarães

Resumo: O espaço das manifestações enredadas com aquelas de junho de 2013, no Brasil, foi vivificado por mediadores que dispunham de corpos ciborgues, provisoriamente no sentido de Lemos (2013). A cada vez que gritam os híbridos, somos interpelados a pensar a especificidade do que entendemos como natureza humana. Para Latour (1994), deve-se devolver ao humano a outra metade de si mesmo: a parte das coisas. De que é feito, então, o humano? Máquinas, objetos, política, religião, economia, natureza; numa conversa revolta e nada determinista. Selvagem e inconstante. O corpo do streamer, no âmbito das manifestações afinadas com as jornadas de junho, seria protótipo dessa constituição. O que agencia essa revoada de entidades? Em que medida esse corpo transgride a si próprio em busca do outro que não é o mesmo - embora o seja por natureza?

Palavras-chave: midiativismo; streamers; etnografia.

Abstract: A flock of entities: what swarms the performance of streamers in the June Journeys (2013)?

- The space of manifestations entangled with those of June 2013 in Brazil was enlivened by mediators who had cyborg bodies, provisionally in the sense of Lemos (2013). Each time the hybrids cry, we are asked to think about the specificity of what we understand as human nature. For Latour (1994) one must give back to the human the other half of himself: the part of things. What, then, is the human made of? Machines, objects, politics, religion, economy, nature; in a tumultuous and not at all deterministic conversation. Wild and fickle. The body of the streamer, as part of the protests tuned with the June days, would be a prototype of this constitution. What agencies this flock of entities? To what extent does this body transgress itself in pursuit of the other that is not the same - although it is by nature?

Keywords: midiativism; streamers; ethnography. 
A terceira fonte de incerteza, proposta por Latour em sua Teoria do Ator-Rede (TAR), parte do reconhecimento dos objetos técnicos, entidades tradicionalmente banidas do espectro coletivo e do pensamento social, como partícipes no curso das ações. O corpo não domesticável do streamer, trazido ao palco à época das primeiras manifestações de 2013, no Brasil, é símbolo da complexa parceria entre o orgânico e os dispositivos cibernéticos. Um corpo mobilizador, provocador, selvagem. Um corpo ciborgue, ao menos em tese, no sentido de Haraway (2000): híbrido de organismo e máquina, que celebra a mutação como potência política. Enxameados pelas ideias de instantaneidade, mobilidade, atuação em rede, produção colaborativa e compartilhamento de conteúdos, os streamers também corporificavam certa cultura do livestreaming, modo de existência em que somos interceptados e constituídos por um fluxo contínuo de informações em tempo real. Por meio de pesquisa de campo realizada durante o período que vai de junho de 2013 a julho de 2014, quando acompanhei a atuação da Mídia Ninja e de outros coletivos de midiativismo no âmbito dos protestos que irromperam no país, pude perceber configurações de agências específicas, permitidas pela existência rebelde, inconstante e instável de um corpo ciborgue, encarnado pelos streamers. Dessas agências faz parte a experimentação estética; a formação de uma rede informacional composta por nós autônomos e, ao mesmo tempo, hiperconectados; a inserção na ação, em diferentes graus; a segurança dos corpos totais e a intimidação do Inimigo.

\section{Experimentação estética}

Destaca-se aqui a precariedade executiva de um catártico-drama, do qual são marcas a personalização do relato, a primazia do ruído, a comunicação imperfeita e a suspensão do espaço-tempo. Embora fosse possível traçar alguns parâmetros de ação semelhantes entre um e outro streamer, ficou evidente que cada um era regente de si próprio. Por outro lado, paradoxalmente, o empoderamento de si, a autorregência, só funcionava porque, mesmo localizados em si, estiveram conectados a outros em rede. É como se cada um se bastasse, mas cada um se bastava justamente porque estava ligado a outros. A potência individual vinha da potência coletiva: dela dependia e, ao mesmo tempo, dela esteve liberta. Era nó autossuficiente e fio vibrando porque ligado a outros nós. Orquestrações externas que quisessem se impor, no sentido de orientar editorialmente, seriam tão improdutivas quanto tentativas de domesticação de animais selvagens, já que provocariam o estado de revolta iminente. O corpo do streamer não era um corpo dócil. Para onde ir, como ir e como se comportar, com quais objetos técnicos, que tipos de narrativa produzir; eram questões resolvidas a cada ação por cada nó, que estendia suas deliberações aos outros nós por reconhecê-los como o mesmo corpo.

No que diz respeito ao arranjo narrativo das transmissões, poderia dizer tratar-se de uma narrativa dramática eufórica, com início, meio e fim. Um catártico-drama, 
mais exatamente. Modelo que, à primeira vista, se aproxima de um esquema narrativo reproduzido com frequência nas matérias telejornalísticas das mais tradicionais, feitas ao vivo ou não ${ }^{1}$. De fato, é possível observar uma dramaturgia do streaming, como lluska Coutinho (2003) observou a dramaturgia do telejornalismo: a instauração do conflito que dispersa as ações - no caso do streaming, o momento de confronto entre policiais e manifestantes-; a distribuição de papéis com base na mítica disputa entre o Bem e o Mal - no geral, manifestantes como mocinhos, policiais como vilões, streamers como heróis-; e o acionamento de lições de moral ao longo do relato - não raro em prol de certa mobilização política. Mas as singularidades do que chamo de catártico-drama, todas as outras mobilidades que aciona, considerando uma rede informacional bem específica, são mais evidentes que os paralelos com uma dramaturgia da narrativa informacional na televisão. A personalização do relato é um dos pontos excedentes. "São imagens que carregam a marca de quem afeta e é afetado de forma violenta, colocando o corpo/ câmera em cena e em ato", como bem coloca Ivana Bentes (2014, p. 333). O tempo do relato, incluídas aí a utilização, disposição e duração de códigos de linguagem, é o tempo do percurso do streamer em sua epopeia pessoal, marcada por descrições das ações e dos cenários onde se desenvolvem; por conversas com manifestantes, outros streamers e pessoas ao entorno do protesto; por enfrentamentos diretos com a polícia; por discursos de mobilização política; pedidos de socorro e pedidos ou cessão de orientação de rota; e momentos de pura deriva silenciosa. Em alguns desses, o silêncio é apenas da fala, enquanto as digitais são impressas na tela do smartphone numa conversa frenética e ruidosa com as vozes textuais do chat da transmissão.

O ruído caracteriza esse catártico-drama instaurando a imperfeição como estética vital das transmissões. Isso vai muito além da questão da velocidade do sinal de internet - muitos streamers utilizavam a rede 3G, que dispunha de pouca estabilidade -, o que já ocasionaria por si só a baixa qualidade das imagens e do som e eventuais interrupções na transmissão. Como o tempo do streaming é o tempo do streamer, as transmissões recebiam as mesmas inscrições que o corpo orgânico. "O meio não é extensão, mas constituição do homem", profere Lemos (2013, p. 161) quando discute a participação das mídias sociais nos levantes sociais da Primavera Árabe. Nesse caso, assim como no campo de análise desta pesquisa, não é possível separar corpo orgânico de aparato técnico. Não há procedimento de purificação que possibilite visualizar um streamer sem o dispositivo móvel de transmissão. E vice e versa. Sendo híbrido, as cronologias de seus rastros estão equalizadas. Ousaria dizer, a título de provocação irônica, que a transmissão é o registro fiel da experienciação do acontecimento pelo streamer. E dessa experienciação fazem parte frequentes interrupções na linearidade do arranjo de ações e imperfeições do ponto de vista de qualquer padrão Global de qualidade. Essas interrupções e imperfeições, mais que pretensos defeitos da transmissão, constituem

1 Sobre a dramaturgia do telejornal, acessar Coutinho (2003). 
uma estética própria: imagens borradas, falas sobrepostas, falha no sinal, findar da bateria do celular, redundância na utilização dos códigos de linguagem, informações desencontradas, narrador não especializado.

Dessa experimentação estética faz parte ainda a construção de uma temporalidade específica, cindida daquela ritmada passo a passo no cotidiano dos transeuntes pelo espaço público. Em partes, o próprio isolamento das áreas de conflito entre manifestantes e policiais promoveu esse deslocamento espaço-temporal, entretanto, outros ingredientes seriam a esse fato adicionados. A sensação que se tinha, no momento do confronto, era a de que a área de atuação dos personagens de cada ato configurava-se como uma zona autônoma. Toda a vida comum acontecia fora dali e as transmissões ao vivo funcionavam dentro mesmo dessa lógica quase ficcional, quase realidade: uma encenação real do real. Isso ficou mais latente nas manifestações que ocorreram no Rio de Janeiro durante a Copa do Mundo de 2014, marcadas pela não adesão em massa da população aos atos convocados. A ritualística dos manifestantes seguia um protocolo tão rígido quanto a ritualística repressora, e o roteiro assim era encenado em locações fortemente emolduradas por cordões de policiais. As cenas seguiam-se na mesma ordem: reunião de policiais, reunião de manifestantes, palavras de ordem mobilizadoras, caminhada, mais palavras de ordem, pequena dispersão, aproximação entre aparelho repressor e manifestantes, enfrentamentos mútuos, agressões mútuas, detenções, reações às detenções e à repressão e dispersão final. Nessa obra ficcional, no sentido de deslocada de uma certa realidade comum, o streamer assumia o papel duplo de ator-cinegrafista, embora seja impossível determinar o quanto há de encenação a rigor nesse papel.

\section{Rede informacional}

Agentes coletivos, pois, tanto simbolicamente como na física da ação, os streamers eram constituídos pelas múltiplas vozes de seus corpos acoplados. Dessas múltiplas vozes, fazia parte o que Ivana Bentes (2014, p. 331) chamou de pós-telespectador de uma pós-tv, conceitos dos quais fazem parte os manifestantes virtuais, "[...] que participam ativamente dos protestos/emissões discutindo, criticando, estimulando, observando e intervindo ativamente nas transmissões em tempo real [...]". Essas vozes eram nós de rede que orientavam rotas dos protestos, sugeriam entrevistados ou imagens, entoavam expressões de estímulo ou gritos de guerra, compartilhavam e viralizavam o link ativo.

As múltiplas vozes que constituíam o streaming, no âmbito dos protestos, já não suportavam a separação entre quem agia e quem olhava, quem transmitia e quem assistia à transmissão. Mesmo que, em alguns momentos, o streamer, empoderado pelo celular, parecesse assumir o papel de protagonista da ação, a exemplo de quando houve detenções de alguns deles pela polícia, gerando comoção em torno de suas figuras, o fato desses atores serem nós de rede era tão definidor de suas não essências individuais que quase poderia 
imaginá-los fantoches do chat de vozes entrando no camburão e sendo, depois, liberados. A clássica prisão de um deles, o Carioca, durante manifestação de 22/07/2013, é emblemática desse ponto. O streamer não interrompeu a transmissão quando estava já dentro do camburão porque isso lhe custaria, simbolicamente, a vida: não seria mais streamer, estariam cortados os fios da rede do qual sua não essência fazia parte. Estaria interrompido o rastro de sua existência. Importante salientar que o celular de Carioca estava com a bateria descarregada ao entrar no camburão e, não fosse algum manifestante emprestar a ele um outro smartphone - um smartphone pessoal somente à primeira vista, então -, nada haveria além de mais um Ninja detido (como outros Ninjas foram detidos nesse mesmo dia, além de alguns manifestantes). Só Carioca saiu carregado da 9a DP.

Outro dos streamers das ruas cariocas, Rodrigo Modenesi, nem de longe lembrava alguma figura associada ao seu codinome, o que ele utilizava no twitcasting: MorreDiabo72. Contou-me, em entrevista (realizada em 3 de julho de 2014), sobre a paixão de estar nas ruas, impulsionado pelo motivo "não sei explicar". A exemplo de alguns, caminhava solitário e não esteve vinculado diretamente a nenhum coletivo de mídia, mas fez questão de exaltar a rede de solidariedade entre streamers nas manifestações. Nas ruas, o acoplamento técnico permitia o surgimento do novo corpo: um solitário nó de rede. Rodrigo contou-me que sua história como streamer começou no Ocupa Cabral. ${ }^{2}$ Sensibilizado, levava água e alimentos para os ocupantes e, certo dia, um celular caiu na sua mão. O corpo estranho repousou ali por alguns minutos; só uma pelada esquentou as coisas. Black blocs versus Ocupantes: a primeira transmissão ao vivo de Modenesi. A primeira digital de MorreDiabo72. Ganhou o codinome de alguém que assistia, nesse dia, a transmissão de outro streamer, o Blackninja. "Olha lá, o Morre Diabo, passou ali". Morre Diabo é, originalmente, Emílio Eduardo da Rocha Devesa, transformado em meme quando foi detido em 2010, na cidade de Cerro Azul (PA), suspeito de ter assassinado a mãe. Incomodado com um dos jornalistas que tentava entrevistá-lo, Emílio lançou o imperativo que faria sucesso. Anos depois, diria alguém, via streaming, sobre Rodrigo: "Igualzinho o "Morre Diabo'". Rodrigo dizia não ser um streamer de linha de frente, de combate. Por isso, mapear os afetos antes do início do ato sempre foi importante para ele: localizava os advogados ativistas, os socorristas, as rotas de fuga possíveis em caso de confronto violento entre manifestantes e policiais. Seu ponto-forte, segundo ele, era a conversa. Rodrigo procurava compreender por que as pessoas presentes no ato estavam naquele lugar, quais eram suas motivações. Além disso, dialogava com quem estava acompanhando o protesto pelo chat da transmissão, não raro solicitando doações em caso de necessidade. Rodrigo potencializava a rede informacional.

Foi no dia seguinte às manifestações do 7 de setembro de 2013 que me dei conta de que a cada streaming uma rede complexa de afetos se formava. Nesse dia, houve

2 Ocupação em frente à residência do então governador do Rio de Janeiro, Sérgio Cabral, no bairro Leblon, durante os meses de junho, julho, agosto e setembro de 2013. 
um ato em frente à embaixada da Rússia, no Leblon, o BeijATO: um protesto carnavalesco e bem-humorado, embora tratasse de assunto dos mais sérios. O gancho eram resoluções homofóbicas do presidente russo Wladimir Putin, mas os manifestantes ampliaram a pauta em protesto aos muitos casos de homofobia existentes também no Brasil. O ponto alto do ato foi a projeção de um vídeo-protesto no muro da embaixada russa, em que diversos ativistas se beijavam. Foi quando alguém no chat começou a conversar comigo. A voz em texto dizia ser da Rússia e me informou que lá um grupo de ativistas também se manifestava no mesmo momento pelas mesmas leis homofóbicas de Putin. Pediu então para informar aos manifestantes brasileiros que de lá os estavam apoiando. Para que a mensagem chegasse a todos, fui a uma das lideranças do ato, que portava um megafone, e pedi que anunciasse o apoio dos ativistas russos. Ela então bradou pelo megafone o anúncio, o que fora aplaudido por todos ali presentes. Através da minha transmissão, o chat também se movimentou em aplausos após acompanhar a cena. A rede que se formou no ato final conectava aplausos intercontinentais através de um celular de última geração e um rústico megafone.

\section{Inserção na ação}

Aqui, há variantes de intensidade consideráveis. Da vestimenta básica para que produtores de conteúdo fossem reconhecidos como tais dentro da manifestação fazia parte um celular ou qualquer outro dispositivo móvel de registro. Complementarmente, capacetes, carregadores portáteis, máscaras e óculos de proteção integravam o corpo ocasionalmente aceito como dócil: aquele que está do lado dos manifestantes, mesmo que os protestos agregassem uma variedade tão grande de perspectivas que, na prática, fosse impossível se identificar com todas elas. Digamos que esse acoplamento fosse uma espécie de crachá de entrada. Foi possível identificar vários modos de inserção na ação, dependendo do tipo de adesão ritualística do corpo individual ao corpo coletivo. Chamaram-me a atenção dois deles: o provisório e o radical. Frequentemente, jornalistas profissionais de grandes empresas de comunicação inseriam-se nas manifestações omitindo o vínculo empregatício, dispensando crachás, canoplas ou marcas de quaisquer tipos - objetos técnicos que iriam entregar uma verdadeira identidade corpo-profissional. O acoplamento padrão - celular em punho - servia, nesse caso, como disfarce. O disfarce servia como proteção contra agressões físicas e simbólicas executadas pelos próprios manifestantes, que associavam o funcionário à empresa, e a empresa à prática, combatida ali, de manipulação de informações a favor de interesses de grandes corporações. A perspectiva não os capturava totalmente, havia adesão parcial ao ritual e sobravam, assim, arestas identificáveis: um caminhar solitário, um rumo incerto, a narração que não saia, um telefonema suspeito. Presenciei alguns momentos em que jornalistas profissionais desencarnaram e logo foram banidos do ritual. Só provisoriamente estiveram encarnados, 
autorizados pelo acoplamento técnico reconhecível. O caso clássico da expulsão de um jornalista da GNews durante os protestos de 7 de setembro de 2013 no Rio de Janeiro também é exemplificador desse desencarne, que virou hit no falatório sobre os atos daquele dia muito em razão de o profissional expulso ser filho do conhecido jornalista carioca Fernando Molica.

Quando se trata de inserção radical na ação, os únicos autorizados plenamente pelo corpo coletivo eram os midiativistas, embora tenham existido alguns poucos jornalistas profissionais bem aceitos. Eles eram reconhecidos pela intimidade com o protesto: portavam-se como músicos de uma orquestra feita de quaisquer números de sonoridades. Cada passo-nota era preciso: o registro certeiro do alto do andaime, do meio do conflito; a narração épica, dramática, com início, meio e fim; a câmera empunhada como arma, de ataque, de defesa; a transmissão ao vivo da prisão; e a troca de informações com outros corpos reconhecidamente midiativistas. Gian Martins, integrante da Mídia Ninja, deu o tom do que caracterizava esse tipo de inserção: "É um jornalismo que está inserido na ação: quando a mídia tradicional está no helicóptero ou assistindo ao longe, em cima dos prédios, a gente está dentro da ação, na linha da frente" ${ }^{3}$ Transmuta-se assim o papel tradicional do repórter: de comunicador dos acontecimentos, aquele que busca eximir-se de suas parcialidades a fim de revelar um fato concreto; para interventor no mundo, aquele que legitima e valoriza sua condição de agência em relação aos fatos. Dessa agência, não é possível descolar as entidades não-humanas.

Diz bem sobre esse modo de inserção no acontecimento o episódio de retomada, em agosto de 2013, da Aldeia Maracanã - antigo Museu do Índio, no Rio de Janeiro - após o julgamento que negou a concessão do prédio para que os indígenas pudessem ocupálo, em favorecimento de obras relacionadas à Copa do Mundo de 2014. "Eles [indígenas] dizem isto: por a gente estar lá gravando, a polícia não abusou como eles sempre fazem", contou-me Paula Daibert, colaboradora da Mídia Ninja. ${ }^{4}$ Thiago Dezan, fotógrafo do mesmo Coletivo, citou o episódio como exemplo de envolvimento radical entre os Ninjas e os indígenas que ocupavam o local:

Thiago Dezan: [...] Fomos de busão com os índios até o Maracanã e entramos, invadimos o prédio juntos, ficamos lá no telhado junto com eles, com o Choque [Batalhão de Polícia] lá embaixo. Os índios falando com a Secretária de Cultura: "Vem aqui". A secretária não queria vir, até que eles falam: "Estamos ao vivo, estamos no Ninja". E aí a Secretária aparece. ${ }^{5}$

Da primeira formação de colaboradores da Mídia Ninja no Rio de Janeiro, fez parte a jornalista Raquel Boechat. O acoplamento técnico era prerrogativa da nova identidade e, como para tantos outros midiativistas, permitia que Raquel estivesse imersa radicalmente

3 Informação fornecida por Gian Martins no dia 17 jul. 2013, via Skype.

4 Informação fornecida por Paula Daibert em 10 set. 2013.

5 Informação fornecida por Thiago Dezan em 10 set. 2013. 
na ação, a exemplo da "Batalha das Laranjeiras" ${ }^{6}$, no dia 11 de julho de 2013. A jornalista contou que estava em um ato em frente ao Palácio da Guanabara, no Rio de Janeiro, segundo ela, um dos mais violentos daqueles tempos. Alguém então avisou: "Tem gente sendo presa no hospital!". Raquel correu até lá. Um primeiro bombardeio já havia ocorrido, muita gente dentro do prédio que tinha passado mal por conta do gás lacrimogêneo estava sendo assistida. Ela e outros midiativistas, além de auxiliar na assistência às vítimas, aproveitavam para carregar equipamentos e upar fotos. "Eu tava no hospital, aí o Massachi [outro midiativista] falou: 'Sabe a minha [bateria], empresta a minha bateria.' Aquelas bateriazinhas que na época ninguém tinha, mas como o Massachi era japonês, o pai dele deu no Réveillon", relembrou ela.7 Foi quando novas bombas de gás começaram a chover na entrada do hospital. A primeira delas caiu bem ao lado de Raquel. Ao correr de volta para o prédio, nem a porta blindex a parou. "Esqueci que tinha a porta, esqueci". ${ }^{8}$

\section{Segurança dos corpos e intimidação do Inimigo}

A intimidade com qualquer objeto de registro, feito corpo, era condição tanto para se proteger de agressões físicas e simbólicas quanto para intimidar, com o celular feito arma, os corpos inimigos. Para os midiativistas, especialmente os streamers, o celular empunhado na direção de um inimigo funcionava como instrumento de contra vigilância e intimidação. Thiago Dezan sintetizou bem a relação dos midiativistas com os dispositivos móveis, que transcendiam a função de ferramentas de registro: "Hoje a gente não precisa mais pegar em armas, nossas armas são câmeras. A gente consegue ter outras linguagens para estabelecer uma disputa simbólica". ${ }^{9}$ Os inimigos mais diretos, presentes nos protestos, eram os policiais, entendidos ali, em sua maioria, como agentes de repressão direta, não raro violenta, e de vigilância do poder repressivo. Na relação entre midiativistas e policiais, o celular, para os primeiros, dizia para os policiais: "Estou te vigiando! Se você me agredir, o mundo inteiro vai ver". Ele vigiava o vigilante e, ao mesmo tempo, intimidava com a promessa muda de que as imagens iriam reverberar provas incontestes de abusos e agressões. A câmera disparava contra os policiais. Os midiativistas, e especialmente os streamers, tornaram-se protagonistas da intimidação, ao aliarem-se a uma câmera combativa que, como frisa Ivana Bentes (2014, p. 334), "[...] usa o poder/potência de exposição on line contra as autoridades policiais, com o monitoramento dos muitos e a multidão em tempo real". Interessante perceber que o registro da ação, como estratégia de segurança e \ou vigilância nos protestos, não era exclusivo dos midiativistas. Também os policiais passaram a fazer uso dessa estratégia, inaugurando um embate direto câmera com câmera. Foram muitas as vezes em que encontrei policiais nos protestos empunhando

6 Raquel escreveu um relato sobre o que ela chamou de "Batalhas das Laranjeiras" no blog do Coletivo Carranca (BOECHAT, 2014)

7 Informação fornecida por Raquel Boechat em 7 jul. 2014.

8 Informação fornecida por Raquel Boechat em 7 jul. 2014.

9 Informação fornecida por Thiago Dezan em 10 set. 2013. 
dispositivos de registro. No dia do primeiro jogo da Copa do Mundo a ser realizado no estádio do Maracanã, no Rio de Janeiro, em 15 de junho de 2014, abordei um policial que estava transmitindo ao vivo a manifestação com um mochilink. Indaguei sobre a função da transmissão. Segundo ele, o motivo era o resguardo de sua segurança, embora parecesse funcionar muito mais como uma estratégia de mídia tática, já que a posse de imagens da manifestação em tempo real conferia aos policiais um maior controle sobre os rumos do ato, bem como a identificação de seus atores, e isso poderia contribuir com o planejamento de ações repressivas imediatas ou futuras. Antes de abordá-lo, empunhei meu celular na direção dele, ação que logo fora retrucada com a mesma disposição: sua câmera foi então direcionada a mim e assim ficou até que eu desviasse minha arma daquela farda. Bentes (2014) destaca justamente essa dupla qualidade que as imagens combativas assumem no protesto: são salvo-conduto, mas também inimigos a neutralizar.

O celular em punho, provocativo, direcionado aos policiais, era responsável, não raro, pelas frequentes idas do streamer Carioca às delegacias. Paradoxalmente, o objeto também assumia a função de protagonista de suas liberações. Em sua detenção emblemática, durante a cobertura da chegada do Papa Francisco à capital do Rio de Janeiro, Carioca seguiu transmitindo sua detenção ao longo do percurso até a delegacia. Em outro momento, durante as manifestações que aconteceram no dia da final da Copa do Mundo, Carioca fora agredido por policiais e seu celular não fora poupado. Após as agressões, o streamer deu continuidade à transmissão e, em tom de provocação, discursou aos ouvidos atentos: "[...] tem 1.7000 pessoas assistindo, já passaram pela transmissão 7.000 pessoas, que viram essa porra, essa babaquice, sacô?". No dia 18 de maio de 2015, Carioca lamentou em post no Facebook a morte de seu chapa: "Sobe aos céus um companheiro. Depois de 3 anos de muita adrenalina nas ruas aguentando tiro, porrada e bomba, nesse final de semana ele parou de funcionar".

A segurança de dados talvez recebesse mais atenção do streamer Rodrigo Modenesi que a proteção de seu corpo orgânico no momento do protesto. Sua preocupação maior era cercar-se de códigos de fala, aplicativos, programas e também do cuidado sobre o que dizer e para quem dizer. Isso para que as informações que por ele circulavam não acabassem entrando em redes inimigas. Nas manifestações, entretanto, a parceria era a básica: celular em punho e óculos de proteção. Num exercício de reversibilidade, Rodrigo me perguntou uma vez se eu me protegia durante os protestos. Ao findar do diálogo, o próprio streamer confirmou a indocilidade, quase selvagem, daqueles corpos. Qualquer acoplamento fora daquele "essencial" era considerado artifício. "O streaming tem essa coisa de... os fotógrafos todos usam capacete, mas os streamers não, né, cara? É engraçado. [...] A gente é mais maluco. O Pardal [outro streamer] não tem capacete. [...] Eu não tenho, o Pardal não tem, o Carranca não tem". ${ }^{10}$

10 Informação fornecida por Rodrigo Modenesi em 3 jul. 2014. 


\section{Considerações finais}

O embaralhamento dos polos envolvidos numa relação especular, do modo como coloca Rancière (2012), transposto à relação jornalista-público, convida o repórter a participar de uma experiência emancipadora. Para isso, a meu ver, é necessário se colocar em margem: o local onde a comutação dos corpos inventa outra poética. Colocar-se em margem difere de colocar-se na margem, porque não estamos pleiteando a existência de uma margem em contraposição à existência de um centro, do qual deveríamos nos afastar caso queiramos participar de uma experiência emancipadora. Concordo com Latour (1994, p. 122) quando diz que "[...] a defesa da marginalidade supõe a existência de um centro totalitário". Tanto um polo quanto outro são ilusões totalitárias, purificações modernas ajustadas ao desejo humano incontrolável de dicotomizar a existência e estabelecer entre os polos relações de dominação e subordinação. Emissores e receptores. Meio e mensagem. Texto e contexto. De fato existem localizados, mas porque associados. Então, tudo que há é margem. Precisamos apenas homologar a vida, e não um lugar específico, como esse local de invenção e criatividades constantes. Por isso, a emancipação do repórter depende de seu posicionamento em margem.

O streamer, no âmbito da manifestação, comportava-se como margem, embora sua emancipação estivesse direcionada a certo local da margem da vida: a vida cultivada dentro da manifestação - que envolve obviamente outras vozes externas ao protesto, como aquelas do chat da transmissão, mas identificadas no geral com as mesmas perspectivas -, e que se encerrava no cordão policial. O enfrentamento à fronteira viria, idealmente, por meio da visibilidade, da posse da palavra. Ivana Bentes acredita no papel dos streamers e midiativistas na profusão de um grito desestabilizador. "[...] tomar posse da palavra é o modo de desestabilizar a partilha do sensível e produzir um deslocamento dos desejos e constituir o sujeito político multidão" (BENTES, 2014, p. 332). Essa multidão nas ruas, heterogênea e autogovernada de maneira policêntrica, inauguraria o que Bentes (ibidem) chama de Revoluções P2P: “Enquanto os poderes se reorganizam para um contra-ataque e guerra em rede, a multidão surfa nesse 'devir mundo do ocupar' através de narrativas colaborativas que mais que difundir as lutas são a própria luta". A ideia de um grito como contra narrativa me inquieta no que diz respeito ao que isso promove de fato. Que tipo de agência desperta? Tornar-se visível é o bastante para gerar tensionamentos de perspectivas e invenções de outras poéticas de vida, considerando que se tornar visível hoje -se posicionar sobre algo - é quase um imperativo? O que nos falta depois de proliferar panfletos diagramados sob o signo do capital? Deleuze (2000, p. 217), quando indagado sobre as potências revolucionárias no âmbito de uma sociedade de controle, dispara: "O importante talvez venha a ser criar vacúolos de não-comunicação, interruptores, para escapar ao controle". Faria parte dos vacúolos a que Deleuze se refere a não disposição dos manifestantes a serem objetos de registro de funcionários de grandes corporações 
midiáticas, numa tentativa de escape às lentes que se combate? Janice Caiafa, com base na leitura de Deleuze, também reflete sobre questão semelhante. Diz ela: "Seria possível tentar informar o mínimo, fugir em alguma medida à insistência para que nos coloquemos, para que nos inscrevamos nesses repertórios? [...] Precisamos de uma zona de alguma sombra e silêncio nos fluxos de comunicação" (CAIAFA, 2011, p. 144). A restauração da prática da recusa, nesse influxo, seria essencial.

Não necessariamente uma zona de silêncio, mas de imperfeição e ruído, o streaming, conduzido pelo corpo nada dócil do streamer, no âmbito daquelas jornadas, clamava, a meu ver, por essa nova poética, também política. Interessante retomar Haraway (2000, p. 96-97) no que ela chama de política do ciborgue: "[...] é a luta pela linguagem, é a luta contra a comunicação perfeita, contra o código único que traduz todo o significado de forma perfeita [...]". É por isso que a política do ciborgue insiste no ruído e advoga a poluição. Pois está reconhecida a potência política do streamer, organismo e máquina, pelas mobilidades e agências que evoca, pela experimentação estética de um catárticodrama enxameado por uma série de vozes, personalistas e coletivas: ruidosas dilacerâncias de padrões. Se não um vacúolo de comunicação, no sentido imaginado por Deleuze, ao menos a recusa à comunicação perfeita, no sentido de Haraway.

Entretanto, a dispersão de perspectivas contrárias, desconfiadas ou indiferentes à manifestação, no âmbito da narrativa, ainda me parece uma questão a ser pensada. Qual o valor das tentativas de diálogo dos streamers com os policiais e a população no geral ao entorno da manifestação, por exemplo? Essa convocatória poderia ser enquadrada, a meu ver, no que Regina Mota (2007) chama de estética da provocação como forma tropicalista de diálogo, a rememorar o que se propunha Glauber Rocha em sua passagem pela televisão, que convocava o espectador para uma queda de braço. Mota (ibidem, p. 4) propõe o conflito como categoria estética que "[...] se manifesta pela construção de um olhar penetrante, que procure o invisível do visível, num diálogo reflexivo que possa libertar, não dominar a sensibilidade do espectador". Alto canibalismo, baixa domesticação.

Os cruzamentos entre perspectivas diferenciadas nas manifestações, no geral, estiveram mais próximos ao confronto dispersante que ao convite provocador, aquele alicerçado no respeito e na consideração do outro como margem da existência do próprio. Isso nos encaminha para discussões ontológicas relacionadas ao campo da comunicação e, mais especificamente, do jornalismo. Se somos margem, seria interessante pensar na possibilidade de assumirmos, em nossa área, uma ontologia inconstante. Nesse reino, me parece tão desafiador - e grandioso! - quanto necessário compreender a cosmologia indígena, seus meandros ontológicos e a inconstância das almas selvagens que no âmbito dessa natureza-cultura partilham a existência com os mais diferentes seres. Já que todo mundo é índio, exceto quem não é, como afirma Viveiros de Castro (2012), não vai ser tão complicado como parece pensar a relação entre jornalistas e xamãs. Como conhece o xamã, quando quer conhecer? 
Lara Linhalis Guimarães é doutora em Comunicação e Cultura pela Eco-UFRJ. É gestora do Coletivo Avenida Independência - Música e Conteúdo e editora-chefe da revista digital Av. Independência. É vice-líder do Grupo de Pesquisa (CNPq) Laboratório de Jornalismo e Narrativas Audiovisuais (Facom-UFJF). Atualmente debruça-se sobre a continuidade da pesquisa doutoral "Uma invenção de jornalismo: ninjas, xamãs e outras perspectivas".

laralinhalis@gmail.com

\section{Referências}

BENTES, I. Estéticas insurgentes e mídia-multidão. Liinc em Revista, Rio de Janeiro, v. 10, n. 1, p. 330343, maio, 2014. Disponível em: <http://revista.ibict.br/liinc/article/view/3552/3049> Acesso em: 15 fev. 2016.

BOECHAT, R. Salve-se quem puder! Dia 5 é você e a urna. Coletivo Carranca, Rio de Janeiro, 2 out. 2014. Disponível em: <http://coletivocarranca.cc/salve-se-quem-puder-dia-5-e-voce-e-urna/> Acesso em: 14 fev. 2016.

CAIAFA, J. Aspectos do múltiplo nas sociedades de comunicação. Contracampo - Revista do Programa de Pós-Graduação em Comunicação - Universidade Federal Fluminense, Niterói, n. 22, fev. 2011.

COUTINHO, I. Dramaturgia do telejornalismo brasileiro: a estrutura narrativa das notícias em televisão. São Paulo, 2003. Tese (Doutorado em Comunicação Social) - Programa de Pós-Graduação em Comunicação Social da Universidade Metodista de São Paulo, 2003.

DELEUZE, G. Conversações. Rio de Janeiro: Editora 34, 2000.

HARAWAY, D. Manifesto ciborgue: ciência, tecnologia e feminismo-socialista no final do século XX. In: SILVA, Tomaz Tadeu da (org). Antropologia do ciborgue: as vertigens do pós-humano. Autêntica: Belo Horizonte, 2000.

LATOUR, B. Jamais fomos modernos. Rio de Janeiro: Editora 34, 1994.

Reagregando o social: uma introdução à teoria do ator-rede. Trad. Gilson César Cardoso de Souza. Salvador: Edufba, 2012; Bauru, São Paulo: Edusc, 2012.

LEMOS, A. A comunicação das coisas: Teoria do ator-rede e cibercultura. São Paulo: Annablume Editora, 2013. (coleção Atopos).

MOTA, R. A terceira margem da televisão. Revista Contemporânea, n. 9, 2007/2. Disponível em: $<$ http://www.contemporanea.uerj.br/pdf/ed_09/contemporanea_n9_02_rmota.pdf $>$. Acesso em: 27 ago. 2015.

RANCIÉRE, J. O espectador emancipado. Trad. Ivone Benedetti. São Paulo: WMF Martins Fontes, 2012. VIVEIROS DE CASTRO, E. A inconstância da alma selvagem. São Paulo: Cosac \& Naify, 2002. 